\title{
Coixol Exerts an Exclusive Glucose-dependent Insulinotropic Effect in $\beta$ TC-6 Cells
}

Rahman M Hafizur $^{1 *}$, Sayed Ali Raza ${ }^{1}$, Abdul Hameed ${ }^{1}$, Achyut Adhikari ${ }^{2}$ and Khaga Raj Sharma ${ }^{2,3}$

${ }^{1}$ Dr. Panjwani Center for Molecular Medicine and Drug Research, International Center for Chemical and Biological Sciences (ICCBS), University of Karachi, Karachi-75270, Pakistan

${ }^{2}$ HEJ Research Institute of Chemistry, International Center for Chemical and Biological Sciences (ICCBS), University of Karachi, Karachi-75270, Pakistan

${ }^{3}$ Central Department of Chemistry, Tribhuvan University, Kritipur, Kathmandu, Nepal

*Corresponding author: Rahman M Hafizur, Dr. Panjwani Center for Molecular Medicine and Drug Research, International Center for Chemical and Biological Sciences, University of Karachi, Karachi-75270, Pakistan, Tel: 922134824934; E-mail: hafizpcmd@yahoo.com

Rec date: May 10, 2015; Acc date: May 11, 2015; Pub date: May 13, 2015

Copyright: ( 2015 Hafizur RM, et al. This is an open-access article distributed under the terms of the Creative Commons Attribution License, which permits unrestricted use, distribution, and reproduction in any medium, provided the original author and source are credited.

\section{Description}

$\beta$ TC-6 cells were incubated in $2 \mathrm{mM}$ and $20 \mathrm{mM}$ glucose in the presence of coixol $(200 \mu \mathrm{M})$ for $60 \mathrm{~min}$ at $37^{\circ} \mathrm{C}$ in Krebs-Ringer Bicarbonate buffer. After incubation, cells were fixed with $2 \%$ paraformaldehyde, permeabilized with $0.5 \%$ Triton X-100, blocked with donkey serum and cells were immunostained for insulin by mouse anti-insulin/Alexa 594-donkey anti-mouse IgG. Images were visualized using a Nikon 90i microscope (Nikon, Japan) and the images were acquired with a Nikon DXM 1200C camera using NISElements image analysis software AR 3.0.

At $2 \mathrm{mM}$ glucose, insulin staining is dispersed throughout the cells (top) suggest that coixol has little to none effects on insulin secretion at low glucose concentration. In sharp contrast, decreased insulin staining was observed by coixol at $20 \mathrm{mM}$ glucose (bottom) suggest that coixol stimulated insulin secretion at high glucose concentration. Additionally, at $20 \mathrm{mM}$ glucose, more insulin staining at the peripheries suggest that the insulin granules are on the way to be secreted. These data suggest that coixol exerts an exclusive glucosedependent insulinotropic effect in $\beta$ TC-6 cells (Figure 1).
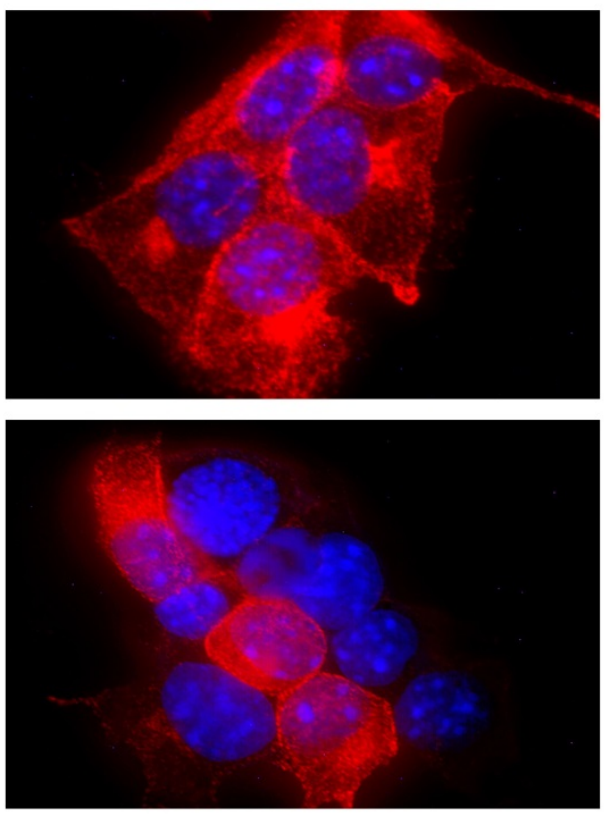

Figure 1: showing coixol exerts an exclusive glucose-dependent insulinotropic effect in $\beta$ TC- 6 cells 